Check for updates

Cite this: RSC Adv., 2017, 7, 30229

Received 7th April 2017

Accepted 5th June 2017

DOI: 10.1039/c7ra03956e

rsc.li/rsc-advances

\section{Facile fabrication of AIE/AIEE-active fluorescent nanoparticles based on barbituric for cell imaging applications $\uparrow$}

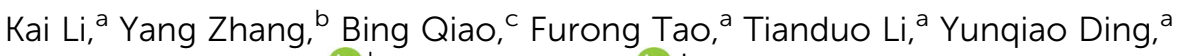 \\ Françisco M. Raymo (iD ${ }^{\mathrm{b}}$ and Yuezhi Cui (D) *a
}

\begin{abstract}
Four barbituric derivatives (1-4), were synthesized with obvious aggregation induced emission (AIE) or aggregation induced emission enhancement (AIEE) behaviors. The optical properties in different states and the mechanisms of the enhanced emission of 1-4 were investigated. We found that there were a large number of globular or blocky nanoparticles with average diameters from 229 to $394 \mathrm{~nm}$ in tetrahydrofuran (THF)/water solutions when the water fraction $\left(f_{\mathrm{w}}\right)$ was $90 \%$. The single crystal data of 2 and 4 reveal that multiple intermolecular interactions restrict the intramolecular motions, and promote the formation of a herringbone arrangement (4), thus permitting intense emission in the aggregate state. In addition, the frontier molecular orbital energy and band gap calculated by density functional theory (DFT) are consistent with the experimental results. Compound 4 is cell-permeable: upon entering the live cells, the dye molecules can accumulate in the lysosomes and turn on the fluorescence.
\end{abstract}

\section{Introduction}

Most luminescent materials suffer from a severe effect called aggregation-caused quenching (ACQ), and their luminescence is quenched in high molecular concentrations or in the aggregation state. ${ }^{\mathbf{1 , 2}}$ These organic materials exhibit relatively strong fluorescence in dilute solution, while only weak or non-emissive fluorescence is detected in the aggregated states or solid states, because strong intermolecular interactions facilitate the nonradiative decay pathway. In contrast, AIE is an opposite phenomenon to ACQ, and luminogens with AIE characters can light up in the aggregated states which conventional fluorophores can never achieve.

Due to the unique fluorescence properties, luminescent materials with AIE/AIEE characteristics have attracted considerable attention since the discovery of the AIE phenomenon by Tang in 2001..$^{3,4}$ AIE/AIEE luminophores have invaluable potential for sensing and bioimaging applications, ${ }^{5-7}$ such as optoelectronic devices, ${ }^{8}$ bio-sensing, ${ }^{9-11}$ explosive sensors, ${ }^{12}$ and stimuli responsive materials. ${ }^{\mathbf{1 3 , 1 4}} \mathrm{Up}$ to now, the range of emission wavelengths of AIE-active molecules that have been developed for

${ }^{a}$ Shandong Provincial Key Laboratory of Fine Chemicals, Qilu University of Technology, Jinan 250353, P.R. China. E-mail: cyz@qlu.edu.cn; Fax: +86 531 89631760; Tel: +8653189631208

${ }^{b}$ Laboratory for Molecular Photonics, Department of Chemistry, University of Miami, 1301 Memorial Drive, Coral Gables, Florida, 33146-0431, USA

${ }^{c}$ Department of Physics, University of Miami, 1301 Memorial Drive, Coral Gables, Florida, 33146-0431, USA

$\dagger$ Electronic supplementary information (ESI) available. See DOI: 10.1039/c7ra03956e cell imaging covers the entire visible light range from blue to red. ${ }^{15-18}$ However, AIE-luminophores with red and near-infrared emission are desired for avoiding possible autofluorescence from biological samples and reducing photocytotoxicity. ${ }^{19-21}$ To address these issues, a few examples have been reported to extend the electronic conjugation of the fluorophores, thus decreasing the energy gap between the electronic ground state and excited state and consequently tuning the absorption and emission characters bathochromically. ${ }^{22}$ Nonetheless, such a strategy has the disadvantages of tedious synthesis, high synthetic workload, interchromophoric induced fluorescence quenching, poor photostability and solubility. ${ }^{23}$ Alternatively, electron-donating (D) and accepting (A) moieties can be incorporated into the design of molecular skeleton. D- $\pi-\mathrm{A}$ molecules typically form charge-transfer (CT) state with a smaller band gap in polar solvents, thus shifting the emission to longer wavelengths. ${ }^{24}$ Barbituric acid derivatives display diverse biological activities, e.g., anesthetic, hypotensive, antibacterial and antitumor activities, and sedative effects. ${ }^{25}$ And they can be readily linked with chromophore substrates through extensively-studied, highly-efficient Knoevenagel reactions, under mild conditions and with no requirement for a special catalyst. ${ }^{26}$ Triphenylamine and barbituric acid derived push- $\pi$-pull systems have been reported by Kim et al. to act as dye molecules. ${ }^{27}$ Shi et al. reported a type of optical probe for $\mathrm{Hg}^{2+}$ via the formation of a mercury(II)barbituric acid coordination complex. ${ }^{28}$ Zhou et al. synthesized and evaluated near-infrared probes with barbituric acid acceptors for in vivo detection of amyloid plaques. ${ }^{29}$

The AIE properties of these compounds have not been investigated except compound 3, and in particular in organism. 
So far, a series of AIE active chromophores have been reported and various mechanistic pathways such as conformational planarization, ${ }^{30}$ J-aggregate formation, ${ }^{31,32}$ twisted intramolecular charge transfer (TICT), ${ }^{33}$ excited state intramolecular proton transfer (ESIPT), ${ }^{34}$ and restriction of intramolecular motion (RIM) have been explored to operate AIE principles by suppressing the intermolecular $\pi-\pi$ stacking

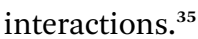

Herein, based on the RIM and intramolecular charge transfer (ICT), ${ }^{36}$ we present a series of AIE/AIEE-active and structurally simple luminogens bearing $\mathrm{D}-\pi-\mathrm{A}$ systems. Barbituric acid is incorporated as the electron-withdrawing group, while triphenylamine and carbazole moieties are installed as the donor groups because of their electron-rich nature. For these compounds, they exhibit obvious AIE/AIEE behaviors and red emission. Their mechanisms of enhanced emission behaviors can be well explained by intermolecular interaction in their crystal structures. With the D- $\pi-\mathrm{A}$ structures, compound 4 emits at the red visible region of the electromagnetic spectrum in its aggregate state. Finally, in vivo cell imaging experiments of compound 4 have been performed in Drosophila S2 cells, and intense intracellular fluorescence signal can be detected with minimal background noise.

\section{Experimental section}

\subsection{Materials}

4-Fluorobenzaldehyde (Jiu Ding Chemistry, 97\%), triphenylamine (Aladdin, 99\%), carbazole (energy, 98\%), N,N-dimethylamino benzaldehyde (Jiu Ding Chemistry, 99\%), barbituric acid (Aladdin, 98\%), 1,3-dimethyl-barbituric acid (Aladdin, 99\%), were used without further purification. DMF was generally dried by molecular sieves $\left(4 \AA\right.$ ) , sodium sands and $\mathrm{CaH}_{2}$ successively, and distilled prior to use. Schneider's Drosophila line 2 [D. mel. (2), SL2] (ATCC® CRL-1963 ${ }^{\mathrm{TM}}$ ) cell line (Drosophila $\mathrm{S} 2$ cell) was purchased from ATCC.

\subsection{Characterizations}

Absorption spectra were recorded using a UV-2500 spectrometer. The fluorescence spectra were measured with an F-4600 fluorescence spectrophotometer. The luminescence quantum yields were determined relative to Coumarin 307 in ethanol solution as a quantum yield standard $(\Phi=0.56)$. Confocal Laser Scanning Microscope (CLSM) experiments were carried out with Leica SP5.

\subsection{Computation}

The geometric and electronic structures of 4 compounds were optimized by density functional theory (DFT) at the B3LYP level. The HOMO and LUMO energy levels are predicated by 6-31G(d) basis set. The compositions of molecular orbits were analyzed using the Gauss View 5.0 program.

\subsection{Synthesis of compounds}

The target luminogens were synthesized by the Knoevenagel condensation of $N, N$-dimethylamino benzaldehyde, $N, N$ - diphenylamino benzaldehyde and $N$-carbazolyl benzaldehyde with (1,3-dimethyl) barbituric acid, respectively (Scheme 1). Then, these luminogens were characterized by ${ }^{1} \mathrm{H}$ NMR (nuclear magnetic resonance spectrometry) and the FTIR (Fourier transform infrared spectrometry). Single crystals of compounds 2 and $\mathbf{4}$ were obtained by slow evaporation of these solutions in the $n$-hexane $/ \mathrm{CHCl}_{3}$ solution at room temperature.

2.4.1. Synthesis of 4 -(9H-carbazolyl) benzaldehyde (1a). A mixture of $9 \mathrm{H}$-carbazole $(1.7 \mathrm{~g}, 0.01 \mathrm{~mol})$, and sodium hydroxide $(1.2 \mathrm{~g}, 0.03 \mathrm{~mol})$ in dry dimethylformamide (DMF) was heated with stirring. Then 4-fluorobenzaldehyde ( $1.5 \mathrm{~g}, 0.012 \mathrm{~mol}$ ) was added, and the reaction mixture was stirred at $90{ }^{\circ} \mathrm{C}$ for $24 \mathrm{~h}$. After cooling to room temperature, the mixture was poured into distilled water and extracted with ethyl acetate. The organic layer was dried with anhydrous magnesium sulfate $\left(\mathrm{MgSO}_{4}\right)$ and concentrated by vacuum evaporation. The crude product was purified by column chromatography using the mixture of petroleum and dichloromethane $(\mathrm{v} / \mathrm{v}=15: 1)$ as an eluent to get the desired compound as a yellow solid $(1.19 \mathrm{~g})$ with a yield of 70.1\%. ${ }^{1} \mathrm{H}$ NMR $\left(\mathrm{CDCl}_{3}\right) \delta(\mathrm{ppm}): 10.13(\mathrm{~s}, 1 \mathrm{H}), 8.16(\mathrm{~m}, 4 \mathrm{H})$, $7.81(\mathrm{~d}, 2 \mathrm{H}), 7.52(\mathrm{~d}, 2 \mathrm{H}), 7.45(\mathrm{t}, 2 \mathrm{H}), 7.34(\mathrm{t}, 2 \mathrm{H})$.

2.4.2. Synthesis of 4-(diphenylamino)-benzaldehyde (1b). $2 \mathrm{ml}$ of dry DMF $(25.7 \mathrm{mmol})$ was added dropwise to $5 \mathrm{ml}$ of phosphorus oxychloride $(54 \mathrm{mmol})$ maintained at $0{ }^{\circ} \mathrm{C}$. After the solution was stirred for $15 \mathrm{~min}$, triphenylamine ( $1 \mathrm{~g}, 4 \mathrm{mmol})$ was added to the above Vilsmeier reagent, and the mixture was heated to $45{ }^{\circ} \mathrm{C}$ for an additional $2.5 \mathrm{~h}$. After cooling, the clear red solution was added dropwise to ice water with stirring, and the resulting mixture was allowed to stand for $2 \mathrm{~h}$. The crude product was collected by filtration, washed with water, and dissolved in dichloromethane. The organic solution was washed with $\mathrm{H}_{2} \mathrm{O}(150 \mathrm{ml})$ and dried over $\mathrm{MgSO}_{4}$. After the solvent was evaporated off, the residue was recrystallized from ethyl acetate to afford aldehyde as a pale yellow crystal with a yield of $0.78 \mathrm{~g}(80 \%) .{ }^{1} \mathrm{H}$ NMR $\left(\mathrm{CDCl}_{3}\right) \delta(\mathrm{ppm}): 9.82(\mathrm{~s}, 1 \mathrm{H})$, $7.69(\mathrm{~d}, 2 \mathrm{H}), 7.35(\mathrm{t}, 4 \mathrm{H}), 7.19(\mathrm{~m}, 6 \mathrm{H}), 7.02(\mathrm{~m}, 2 \mathrm{H})$.

2.4.3. Synthesis of 5-( $\mathrm{N}$-carbazole styryl)-barbituric acid (1). A mixture of barbituric acid $(0.128 \mathrm{~g}, 1 \mathrm{mmol})$ and $N$-carbazolyl benzaldehyde $(0.274 \mathrm{~g}, 0.7 \mathrm{mmol})$ in acetic $(15 \mathrm{ml})$, acetic anhydride $(15 \mathrm{ml})$ and benzene $(5 \mathrm{ml})$ was added to dissolve the undissolved $N$-carbazolyl benzaldehyde, then the mixture was refluxed for $2 \mathrm{~h}$. The reaction was cooled to room temperature and the solid particles were filtered. The product was then purified by recrystallization with acetic acid to give $0.30 \mathrm{~g}$ with $75 \%$ yield. ${ }^{1} \mathrm{H}$ NMR (DMSO) $\delta(\mathrm{ppm}): 11.43(\mathrm{~s}, 1 \mathrm{H}), 11.30(\mathrm{~s}, 1 \mathrm{H})$, $8.43(\mathrm{~d}, 2 \mathrm{H}), 8.39$ (s, 1H), 8.26 (d, 2H) 7.78 (d, 2H), $7.46(\mathrm{~m}, 2 \mathrm{H})$, $7.34(\mathrm{~m}, 4 \mathrm{H})$.

2.4.4. Synthesis of 5-(4-dimethylamino styrene)-1,3dimethyl-barbituric acid (2). A mixture of 1,3-dimethylbarbituric acid $(0.78 \mathrm{~g}, 5 \mathrm{mmol})$ and $N, N$-dimethylamino benzaldehyde ( $0.745 \mathrm{~g}, 5 \mathrm{mmol})$ in acetic $(5 \mathrm{ml})$ and acetic anhydride $(5 \mathrm{ml})$ was refluxed for $2 \mathrm{~h}$. The reaction was cooled to room temperature and the solid particles were filtered. The product was then purified by recrystallization with acetic acid to give $0.97 \mathrm{~g}$ with $68 \%$ yield. ${ }^{1} \mathrm{H}$ NMR $\left(\mathrm{CDCl}_{3}\right) \delta(\mathrm{ppm}): 8.45(\mathrm{~s}, 1 \mathrm{H})$, $8.40(\mathrm{~d}, 2 \mathrm{H}), 6.76$ (d, 2H), 3.41 (d, 6H), 3.17 (s, 6H). 

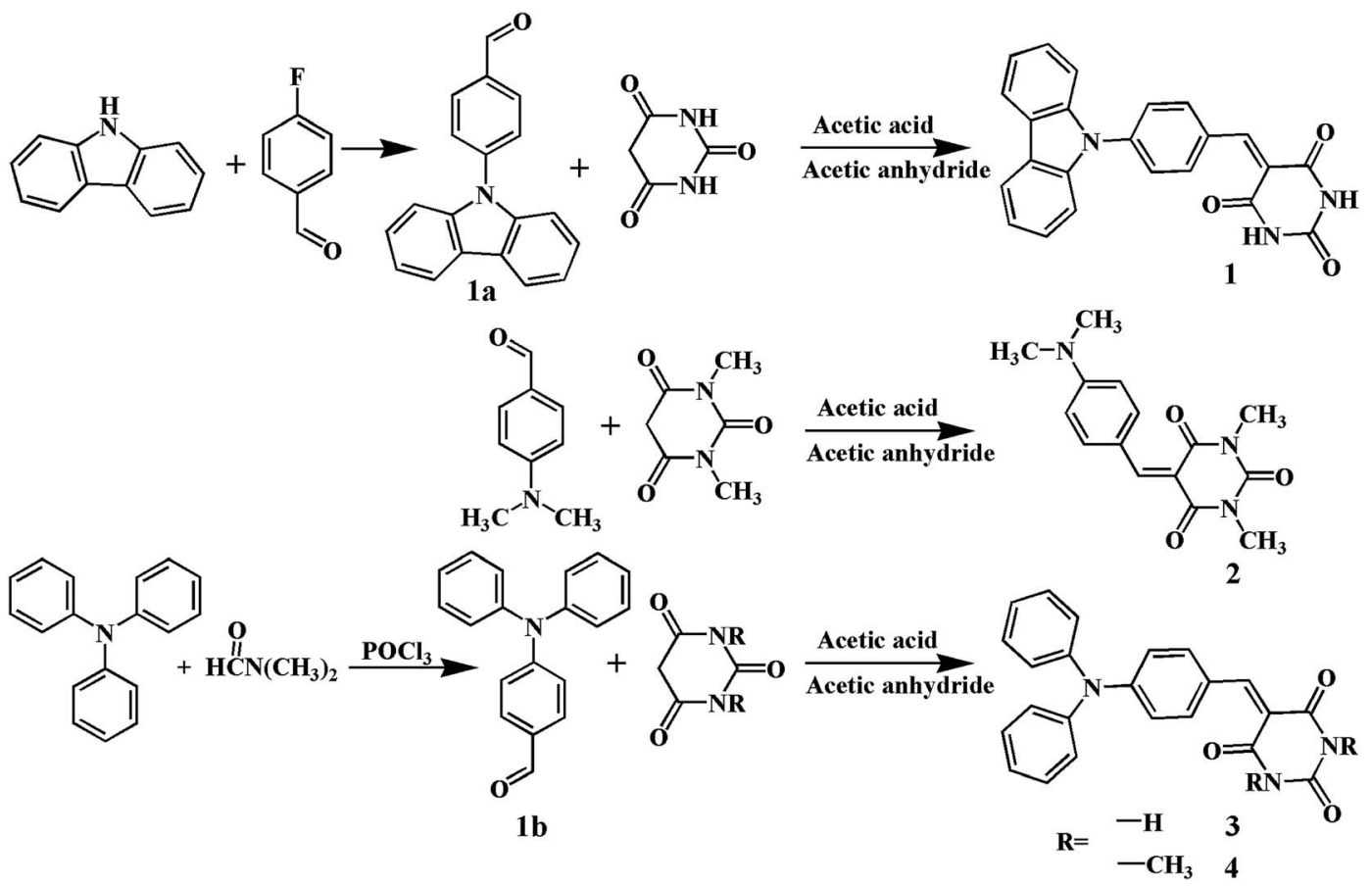

Scheme 1 Synthetic routes to $1-4$.

2.4.5. Synthesis of 5-(4-diphenylamino styrene)-barbituric acid (3). A mixture of barbituric acid (0.384 g, $3 \mathrm{mmol})$ and 4(diphenylamino) benzaldehyde $(0.447 \mathrm{~g}, 3 \mathrm{mmol})$ in acetic (5 $\mathrm{ml}$ ) and acetic anhydride $(5 \mathrm{ml})$ was refluxed for $2 \mathrm{~h}$. The reaction was cooled to room temperature and the solid particles were filtered. The product was then purified by recrystallization with acetic acid to give $0.87 \mathrm{~g}$ with $78 \%$ yield. ${ }^{1} \mathrm{H}$ NMR (DMSO) $\delta$ (ppm): 11.21 (s, 1H), 11.07 (s, 1H), 8.28 (d, 2H), $8.15(\mathrm{~s}, 1 \mathrm{H})$, $7.44(\mathrm{t}, 4 \mathrm{H}), 7.25(\mathrm{~m}, 6 \mathrm{H}), 6.76(\mathrm{~d}, 2 \mathrm{H})$.

2.4.6. Synthesis of 5-(4-diphenylamino styrene)-1,3dimethyl-barbituric acid (4). A mixture of 1,3-dimethylbarbituric acid (0.163 g, $1 \mathrm{mmol}$ ) and 4-(diphenylamino) benzaldehyde $(0.276 \mathrm{~g}, 1 \mathrm{mmol})$ in acetic $(5 \mathrm{ml})$ and acetic anhydride $(5 \mathrm{ml})$ was refluxed for $2 \mathrm{~h}$. The reaction was cooled to room temperature and the solid particles were filtered. The product was then purified by recrystallization with acetic acid to give $0.27 \mathrm{~g}$ with $70 \%$ yield. ${ }^{1} \mathrm{H}$ NMR $\left(\mathrm{CDCl}_{3}\right) \delta(\mathrm{ppm}): 8.44(\mathrm{~s}, 1 \mathrm{H})$, $8.24(\mathrm{~d}, 2 \mathrm{H}), 7.38(\mathrm{t}, 4 \mathrm{H}), 7.23(\mathrm{~m}, 6 \mathrm{H}), 6.95(\mathrm{~d}, 2 \mathrm{H}), 3.40(\mathrm{~d}, 6 \mathrm{H})$.

\subsection{Cell culture and imaging}

Drosophila melanogaster S2 cells were cultured in Shields and Sang M3 Insect Medium $\left(39.4 \mathrm{~g} \mathrm{~L}^{-1}\right)$ with fetal bovine serum $(15 \%, \mathrm{v} / \mathrm{v})$, penicillin-streptomycin solution $(1 \% \mathrm{v} / \mathrm{v}$ at a final concentration of $100 \mathrm{k}$ units per $\mathrm{L}$ penicillin and $100 \mathrm{mg} \mathrm{L}^{-1}$ streptomycin) and $\mathrm{KHCO}_{3}\left(0.5 \mathrm{~g} \mathrm{~L}^{-1}\right)$ and incubated at $22{ }^{\circ} \mathrm{C}$. The cells were seeded in glass-bottom plates at a density of $5 \times$ $10^{4}$ cells per $\mathrm{mL}$ and incubated for $30 \mathrm{~min}$ at $22^{\circ} \mathrm{C}$. A DMSO solution of $4(10 \mathrm{mM})$ was diluted with phosphate buffered saline (PBS) to a final concentration of $0.1 \mathrm{mM}$. The cultured cells were incubated with a PBS solution $(50 \%, \mathrm{v} / \mathrm{v})$ of compound 4 (0.1 mM) for 2 hour, washed three times with PBS
$(100 \mu \mathrm{L})$ and imaged. All images were recorded with a Leica SP5 confocal laser scanning microscope (CLSM). ${ }^{37}$

For the colocalization experiments, a PBS solution $(50 \%, \mathrm{v} / \mathrm{v})$ of $4(0.1 \mathrm{mM})$ was added to the cells for 2 hour, and washed three times with PBS $(100 \mu \mathrm{L})$. Then PBS solutions $(50 \%, \mathrm{v} / \mathrm{v})$ of 4',6-diamidino-2-phenylindole (DAPI) or Lysotracker Blue (10 $\mu \mathrm{M})$ were added to the cells for $30 \mathrm{~min}$ and washed three times with PBS $(100 \mu \mathrm{L})$. The fluorescence of DAPI or Lysotracker Blue was recorded in blue channels $\left(\lambda_{\mathrm{Ex}}=405 \mathrm{~nm}, \lambda_{\mathrm{Em}}=420-470\right.$ $\mathrm{nm})$, the fluorescence of compound $\mathbf{4}$ was recorded in red channel $\left(\lambda_{\mathrm{Ex}}=488 \mathrm{~nm}, \lambda_{\mathrm{Em}}=500-600 \mathrm{~nm}\right)$.

\section{Results and discussion}

\subsection{Optical properties}

Optical properties of the compounds 1-4 were investigated by UV-vis and fluorescence spectroscopy. All the compounds demonstrate good solubility in typical organic solvents such as THF, DMF, chloroform, and DMSO, but they are hardly soluble in water. The UV-vis absorption spectra of compounds 1-4 are presented in Fig. 1.

As shown in Fig. 1, they exhibit quite similar absorption spectra in THF. The absorption bands ranging between 270 and $350 \mathrm{~nm}$ are assigned to $\pi-\pi^{*}$ electronic transition of the respective benzene ring, carbazole and diphenylamine units. The molecules exhibit strong absorption peaks at 412, 454, 454, and $458 \mathrm{~nm}$ for 1-4, respectively, which can be attributed to intramolecular charge transfer (ICT) from the carbazole, dimethylamino and diphenylamine units to the (1,3-dimethyl) barbiturate moiety. ${ }^{38}$ Density functional theory (DFT) calculations also confirmed the ICT possibilities of these compounds (Fig. 9). 


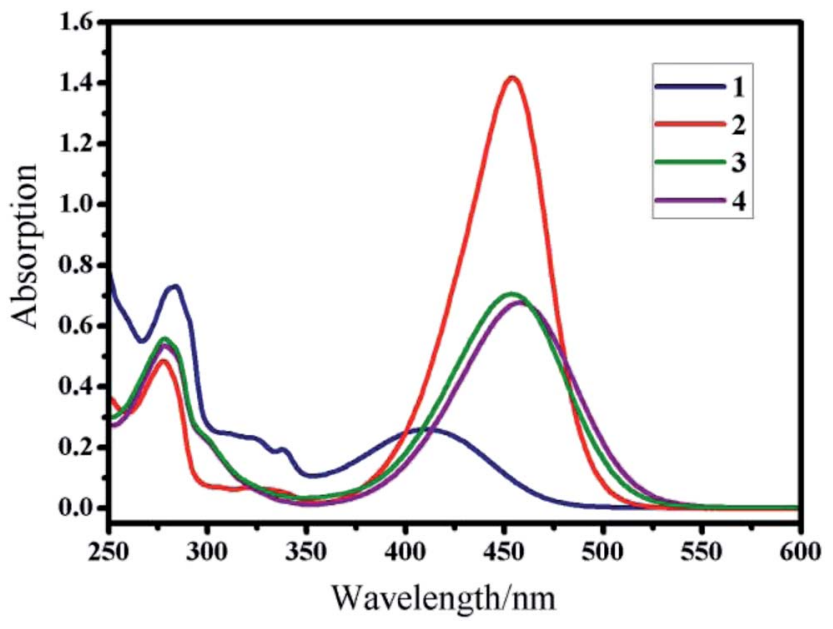

Fig. 1 UV-visible absorption spectra of 1-4 (24 $\mu \mathrm{M})$ in THF solution.

We investigated the emission of the four compounds in different states. As shown in Table 1, in pure THF with low concentration, these compounds are almost molecularly isolated without any interactions between the adjacent molecules. All the molecules exhibit distorted conformation due to the intramolecular steric hindrance..$^{39}$ The optimized geometric structure of $\mathbf{1}$ show twisted conformation with a dihedral angle of $56.63^{\circ}$ (Fig. S17†). Thus the molecules are not in good conjugation state, which contribute to the shortest emission wavelength (Fig. 2).

The molecules of 2 in the crystal state are arranged so regularly that the rotatable single bonds are locked due to the multiple intermolecular interactions (Fig. 6). These interactions help to further solidify the molecular conformation in the aggregated state, and they block the nonradiative pathways. ${ }^{40}$

\subsection{AIE/AIEE properties}

Emission spectra of 1-4 in THF and THF/water media were recorded to facilitate the aggregation due to their water insoluble characters (Fig. 3). Therefore, the luminogens are able to aggregate in the aqueous mixtures with high water fractions $\left(f_{\mathrm{w}}\right)$. Mixture of THF and water was used for preparation of nanoaggregates by increasing the percentage of water in the THF solution. Their fluorescence (FL) spectra with different $f_{\mathrm{w}}$ are shown in Fig. 3, and the changes of FL peak depict the variation tendency of fluorescence intensity with different $f_{\mathrm{w}}$.

We can see from the photographs that in pure THF with low concentration, compounds $\mathbf{2}$ and $\mathbf{4}$ are nonemissive, while $\mathbf{1}$ and 3 show weak emission in dilute pure THF (Fig. 4). In Fig. 3, the data indicate that all chromophores exhibit different fluorescent behaviors in mixed solvents with different $f_{\mathrm{w}}$. The FL intensities of $\mathbf{2}$ and $\mathbf{4}$ in pure THF are so low that only weak signals are recorded with maxima at 542.8 and $633.4 \mathrm{~nm}$, respectively (Fig. $3 \mathrm{~b}$ and d). Then they start to increase when the $f_{\mathrm{w}}$ is increased to $70 \%$ and $60 \%$, respectively. The solutions emit orange and red light with $\lambda_{\mathrm{Em}}$ at 603.4 and $627.2 \mathrm{~nm}$ at $f_{\mathrm{w}}=$ $90 \%$, respectively. The FL intensity of 2 enhances 23.6 -fold and the fluorescence quantum yield $\left(\Phi_{\mathrm{F}}\right)$ increases from $0.4 \%$ to $8.2 \%$ when $f_{\mathrm{w}}$ increases from $0 \%$ to $90 \%$. While the FL intensity of 4 enhances 42.2 -fold ( $\Phi_{\mathrm{F}}: 0.1 \%$ to $\left.3.2 \%\right)$. These data demonstrate $\mathbf{2}$ and $\mathbf{4}$ are AIE-active molecules.

The compounds $\mathbf{1}$ and $\mathbf{3}$ display a different fluorescent behavior from 2 and 4 in mixed solvents with different $f_{\mathrm{w}}$. In pure THF, 1 and 3 show weak emission at 592.6 and $619.4 \mathrm{~nm}$ (Table 1). The emission of 3 is obviously red-shifted $(26.8 \mathrm{~nm})$ compared with $\mathbf{1}$, because the diphenylamino group is a much stronger electrondonor than the carbazole group, resulting in an increase in the HOMO energy. ${ }^{41}$ And the subsequent theoretical calculations support this speculation (Fig. 9). The FL intensity of 1 and 3 gradually decreases when $f_{\mathrm{w}}<70 \%$ which may be caused by ICT. ${ }^{42}$ When $f_{\mathrm{w}}>70$, the FL intensity increases rapidly. The FL intensity of 1 increases 3.3-fold and the $\Phi_{\mathrm{F}}$ increases from $5.4 \%$ to $11.4 \%$ when $f_{\mathrm{w}}$ increases from $0 \%$ to $90 \%$, while the $\mathrm{FL}$ intensity of 3 enhances 6.5 -fold ( $\Phi_{\mathrm{F}}: 1.8 \%$ to $\left.7.4 \%\right)$. These date demonstrate that 1 and 3 are AIEE-active molecules.

It is also noted that the emission peak varies with $f_{\mathrm{w}}$ (Fig. 3, right). The emission peak of 2 is red-shifted from 542.8 to $603.4 \mathrm{~nm}$. The large red-shift may be caused by $\pi-\pi$ staking when the 2 aggregate. However, compound 3 exhibits a more complicated tendency with the increase of $f_{\mathrm{w}}$. The emission peak of 3 red-shifts from $619.4 \mathrm{~nm}$ to $648.4 \mathrm{~nm}$ when $f_{\mathrm{w}}$ increases from $0 \%$ to $70 \%$. Furtherly, it blue-shifts to $624.4 \mathrm{~nm}$ as $f_{\mathrm{w}}$ increase to $90 \%$. When $f_{\mathrm{w}}$ is no more than $70 \%$, molecule 3 is still completely dissolved in the mixtures, and increased $f_{\mathrm{w}}$ enhances the polarity of mixture, generating red-shift emission due to the ICT effect. As $f_{\mathrm{w}}$ reaches $70 \%$, due to the decreased solvating power, molecule 3 starts to aggregate, resulting in less

Table 1 Optical properties of compounds 1-4

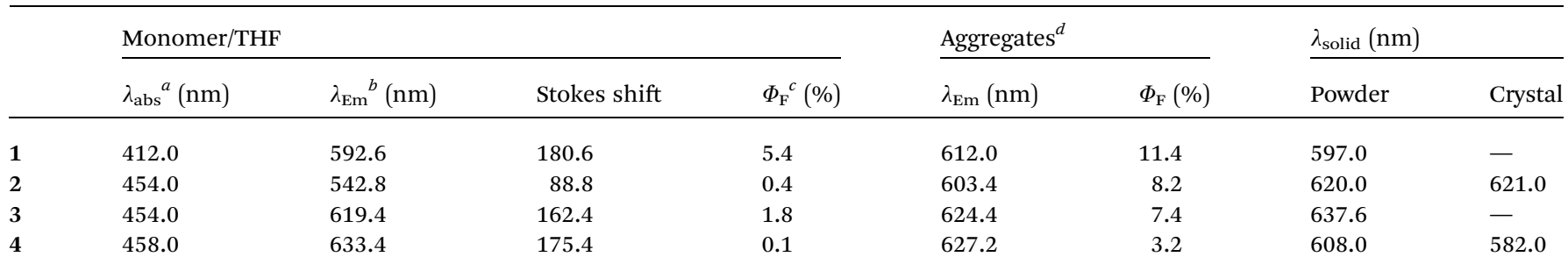

${ }^{a}$ The maxima absorption peak. ${ }^{b}$ The maxima emission peak, in dilute THF solution $(24 \mu \mathrm{M}) .{ }^{c}$ Fluorescence quantum yields were determined relative to Coumarin 307 in ethanol solution as quantum yield standard $(\Phi=0.56){ }^{d}$ In mixed water/THF solution with $f_{\mathrm{w}}=90 \%$. 

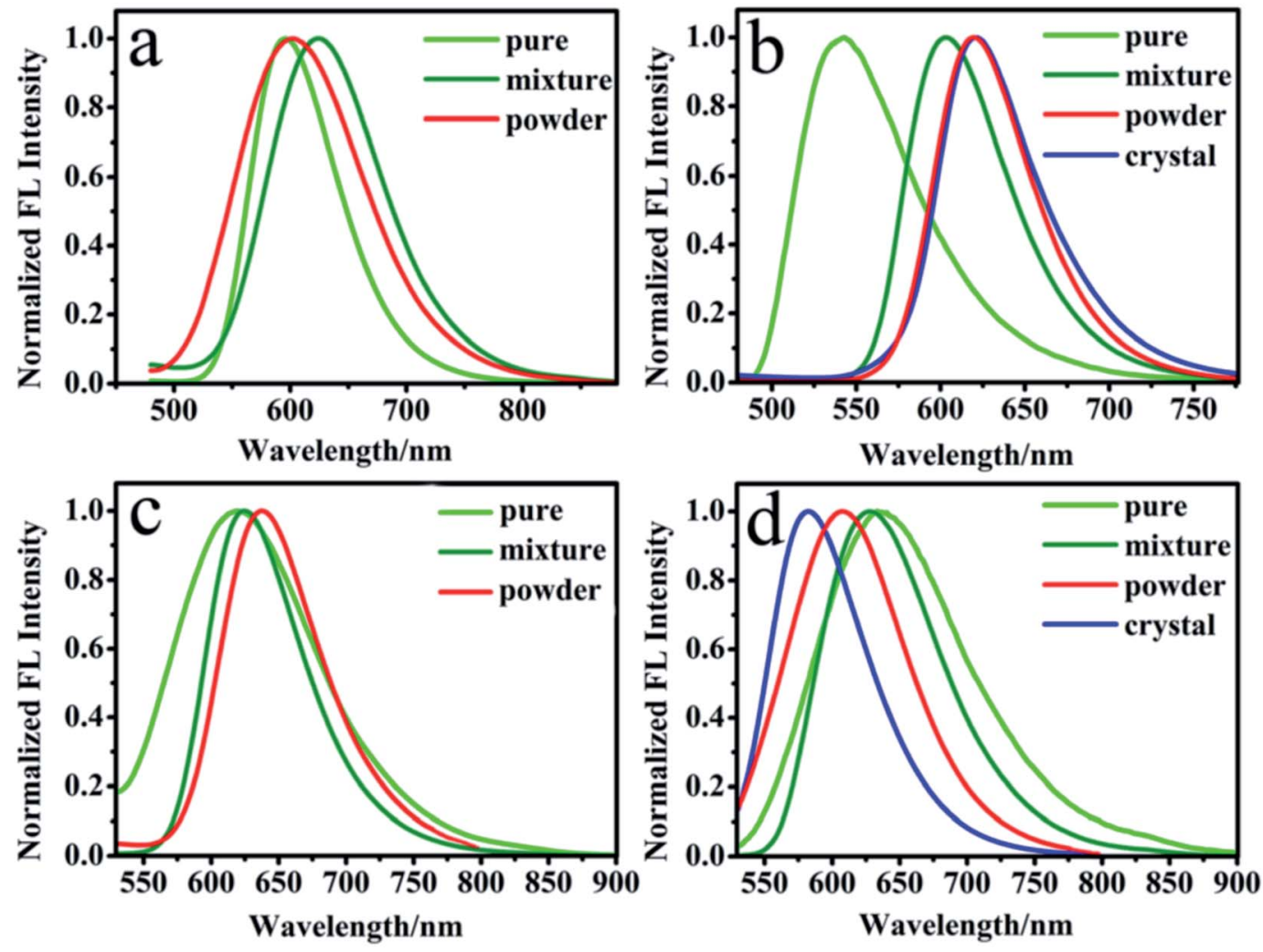

(a)
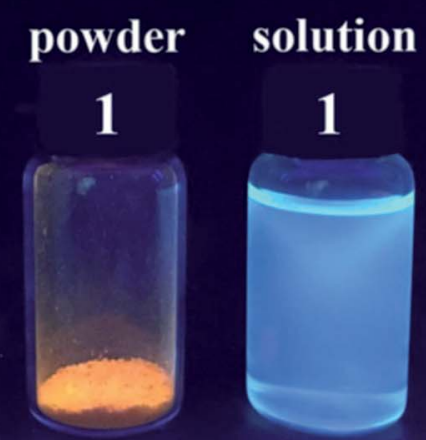

(c)

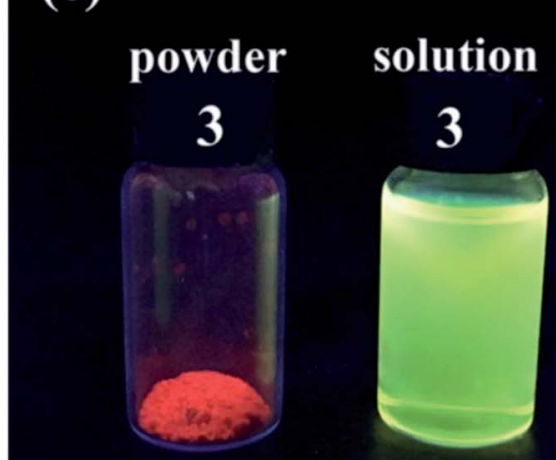

(b)

\section{crystal powder solution}

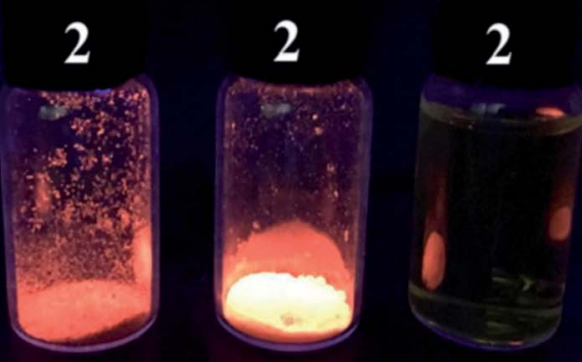

(d)
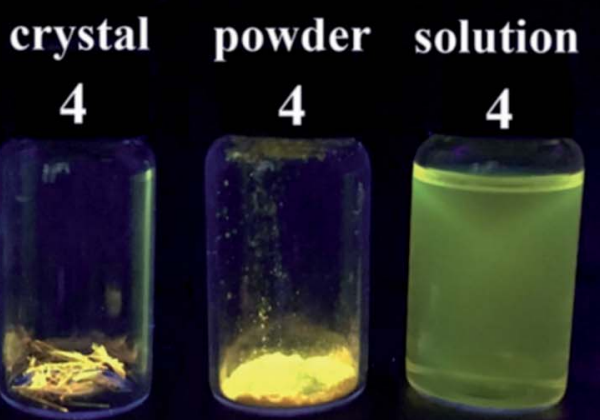

4

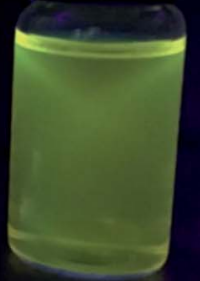

Fig. 2 Normalized FL spectra and photographs of (a) 1, (b) 2, (c) 3 and (d) 4 in different state (THF solution, solid powders, crystal). 

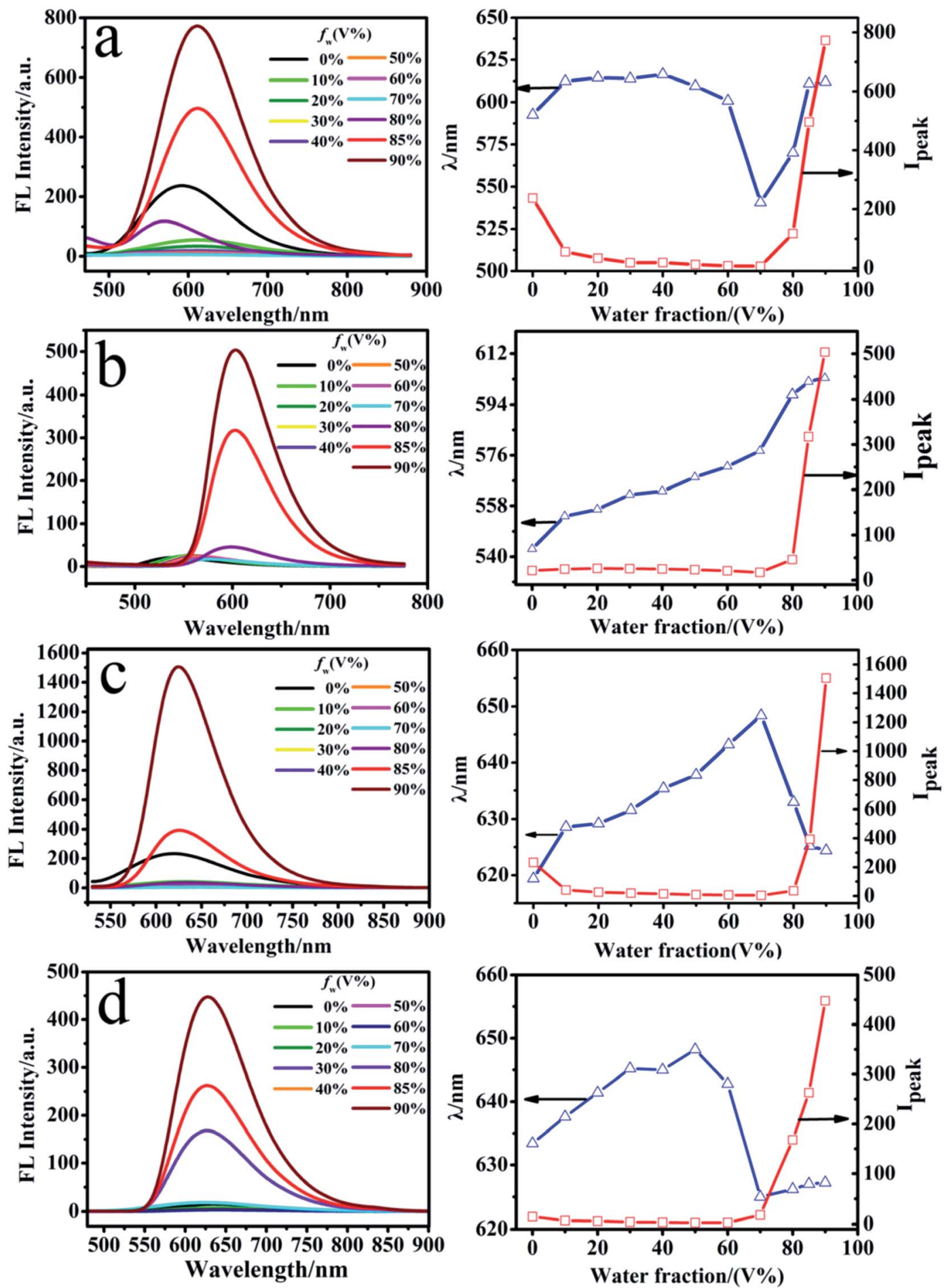

Fig. $3 \mathrm{FL}$ spectra of (a) 1, (b) 2, (c) 3 and (d) 4 in THF/ $\mathrm{H}_{2} \mathrm{O}$ mixtures with different water fraction ( $f_{\mathrm{w}}$ ) (left); excitation wavelength $=450 \mathrm{~nm}$, $398 \mathrm{~nm}, 510 \mathrm{~nm}, 460 \mathrm{~nm}$. Plot of relative FL peak location (blue) and emission intensity (red) of 1-4 versus the water fraction in the aqueous mixtures (right).

polar micro-environment for the luminogens because of selfwrapping. Thus reversely giving blue-shifted emissions. ${ }^{43,44}$ Compounds 1 and 4 behave similarly to 3.

The morphology and size of the nanoaggregates in the THF/ $\mathrm{H}_{2} \mathrm{O}$ solvent with different $f_{\mathrm{w}}$ were detected by scanning electron microscopy (SEM) and dynamic light scattering (DLS) (Fig. 5), which show the presence of spherical and blocky aggregates.

As shown in Fig. 5 , at $f_{\mathrm{w}}=90 \%$, the average diameters $(d)$ of the nanoaggregates for 1-4 are $394.2,229.3,382.4$ and $346 \mathrm{~nm}$, 


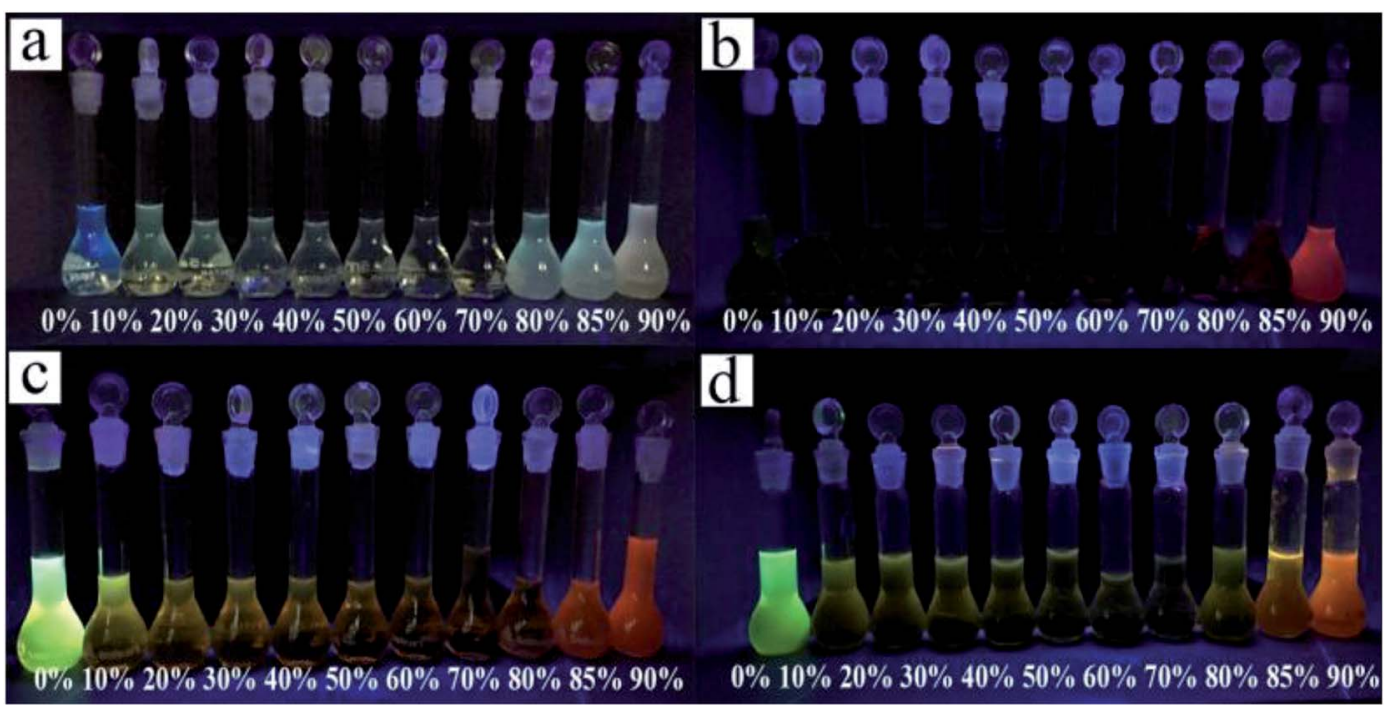

Fig. 4 Photographs of (a) 1, (b) 2, (c) 3 and (d) 4 at $f_{\mathrm{w}}=0 \%$ to $90 \%$ under $365 \mathrm{~nm}$ UV light illumination.

respectively. The size of nanoaggregates decrease gradually with increasing $f_{\mathrm{w}}$ (Table $\mathrm{S} 1 \dagger$ ), due to the rapidly decreased solvating power of the mixed solvent $\left(\mathrm{THF} / \mathrm{H}_{2} \mathrm{O}\right) \cdot{ }^{43}$ These data indicate that the enhanced emission of compounds is related to the formation of nanoaggregates.

\subsection{Single crystal structure}

Single crystal X-ray diffraction (SXRD) analysis can provide a direct insight into the molecular conformation and the packing structure of a compound. Compound 2 adopts planar construction, and it has good planarity (Fig. 6b). The dihedral angles of 4 between the terminal unit and the phenyl ring are $59.50^{\circ}$ and $87.23^{\circ}$, respectively, which indicates that compound 4 shows a large torsion (Fig. 7b).

As shown in Fig. 6b, in crystal 2, the $\mathrm{C}-\mathrm{H} \cdots \mathrm{O}$ interaction between carbanyl group and methyl group links the adjacent molecules into one-dimensional linear chain, and the distance of $\mathrm{C}-\mathrm{H} \cdots \mathrm{O}$ interaction are $2.581 \AA$ A Then, the adjacent chains are further linked into two-dimensional network structures through $\mathrm{C}-\mathrm{H} \cdots \mathrm{O}$ interactions (the distances are 2.548 and $2.665 \AA$, respectively) between carbanyl groups and methyl groups, C$\mathrm{H} \cdots \mathrm{H}-\mathrm{C}(d=2.310 \AA)$ and two $\mathrm{C}-\mathrm{H} \cdots \pi$ interactions $(d=2.896$ $\AA)$. These interactions make the molecular conformations stable.

As depicted in Fig. 7, the molecule 4 adapts a twisted conformation due to the steric hindrance between the diphenylamino unit and the 1,3-dimethylbarbiturate moiety. And the adjacent molecules are connected via intermolecular $\mathrm{C}-\mathrm{H} \cdots \mathrm{O}$ interactions into one-dimensional linear bands, the distances of $\mathrm{C}-\mathrm{H} \cdots \mathrm{O}$ interactions are $2.531 \AA$ and $3.211 \AA$, respectively. As shown in Fig. 7c, the adjacent molecules in crystal $\mathbf{4}$ are herringbone stacking by $\mathrm{C}-\mathrm{H} \cdots \mathrm{O}(d=2.564 \AA), \mathrm{C}-\mathrm{H} \cdots \pi(d=$ $2.762 \AA), \mathrm{C}=\mathrm{O} \cdots \mathrm{C}$ and $\mathrm{C}=\mathrm{O} \cdots \mathrm{N}$ interactions $(d=2.973 \AA$, $3.048 \AA$, and $3.155 \AA$ ). The crystal also possesses a $\pi-\pi$ interaction between two terminal phenyl of adjacent molecules and the distance is $3.384 \AA$ in Fig. 7d. These interactions make their configuration stable. ${ }^{40}$

\subsection{Mechanisms of enhanced emission}

As discussed above, compounds 1-4 are practically nonemissive when molecularly dissolved in solvents due to the active intramolecular rotations and vibrations. The intermolecular interactions are mainly reflected in restriction of intramolecular motions and some specific molecular stacking modes, such as Jaggregation and herringbone stacking, ${ }^{45,46}$ which can restrain the radiative decay process and promotes the enhanced emission behavior. On the contrary, the $\mathrm{H}$-aggregation, where molecules are arranged in face-to-face type to form excimers or exciplexes, can promote the nonradiative deactivation process. ${ }^{47}$

In diluted solutions, the molecules 1-4 are almost isolated and adopt a twisted conformation due to the steric hindrances in the molecules which decreases the $\pi$-conjugation. The intramolecular motions such as rotations, vibrations, stretching, will consume the energy of excited state and suppress the radiative decay process. While in the aggregated state, there are numerous intermolecular interactions between the hydrogen and oxygen, carbon or nitrogen atoms; besides, some $\pi-\pi$ stacking or $\mathrm{C}-\mathrm{H} \cdots \pi$ interactions exist in the aggregate structures. These interactions lead to the planarity and stability of molecular conformation. Under the effect of intermolecular interactions, intramolecular vibrations or rotations are locked, and the molecular conformations are more rigid and planar. These motions are suppressed greatly due to the spatial constraint, which blocks the nonradiative decay pathway and promotes the radiative decay of the excited state..$^{33}$

The restriction of intramolecular motion (RIM) induced by the molecular aggregation can be considered as the mechanism of enhanced emission for 1-3. Furthermore, the molecule $\mathbf{4}$ has a herringbone stacking conformation in crystal. Thus the enhanced emission of $\mathbf{4}$ was attributed to the synergetic effects of the herringbone stacking formation and RIM. Therefore, the phenomenon of fluorescence enhancement can be ascribed as the formation of nanoaggregates of molecules 1-4 at high $f_{\mathrm{w}}$ according to the SEM and DLS results. 

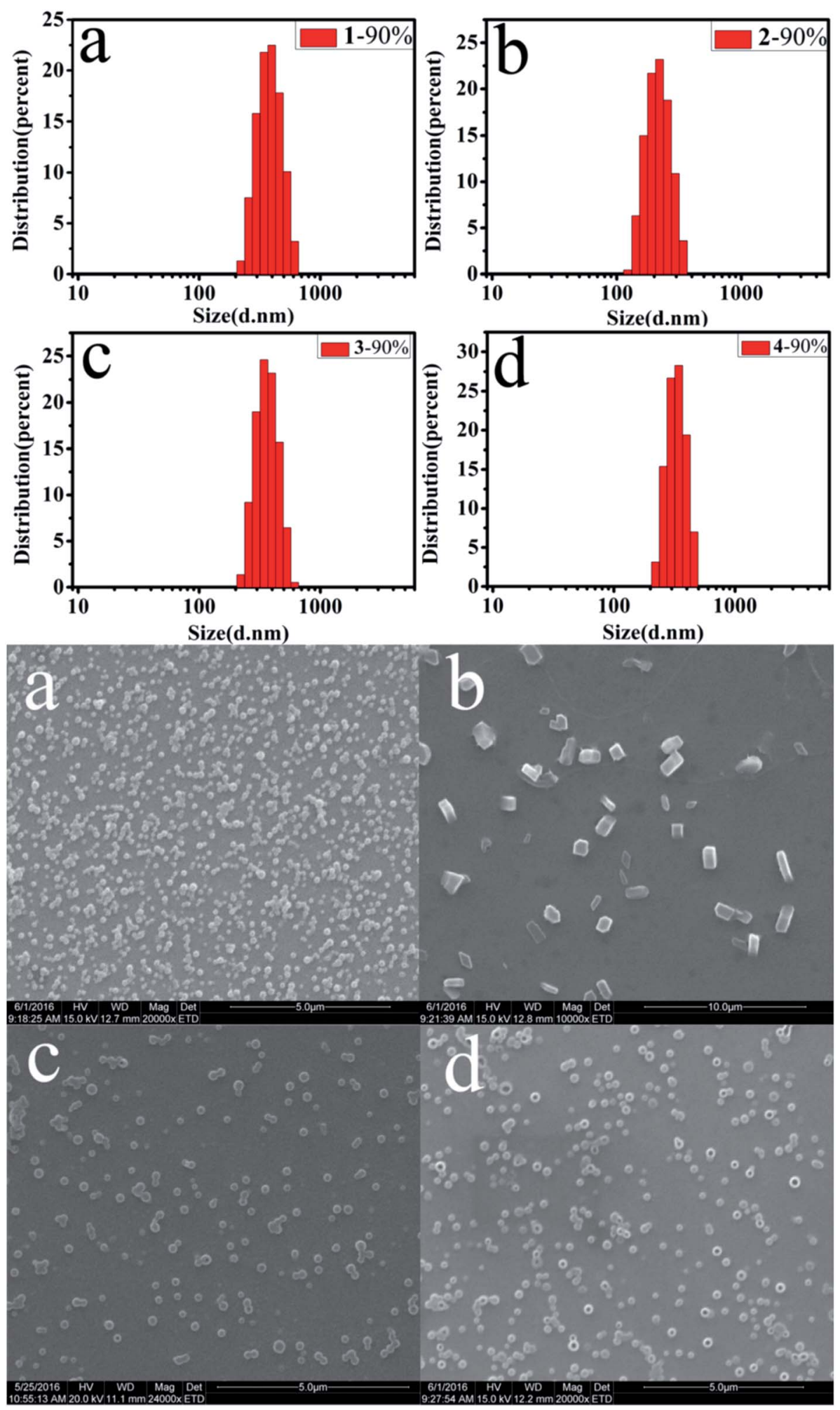

Fig. 5 SEM images and particle size distributions of (a) 1 , (b) 2, (c) 3 and (d) 4 in THF/ $\mathrm{H}_{2} \mathrm{O}$ mixtures $\left(f_{\mathrm{w}}=90 \%\right)$ at concentrations of $24 \mu \mathrm{M}$.

\subsection{In vivo imaging}

Before exploring the application for live cell imaging, we examined the biocompatibility of compound 4. Comparing the morphologies of S2 cells with (Fig. 8a) and without (Fig. S19†) the presence of compound $\mathbf{4}$, they are almost identical shape in the white-filed channel, which suggest its non-cytotoxic feature. The excellent biocompatibility of compound 4 motivated us to further investigate their application in cell imaging. The time scanning spectra of compound 4 at $f_{\mathrm{w}}=0.9$ were shown in Fig. S18. $\dagger$ As can be seen, the fluorescence 


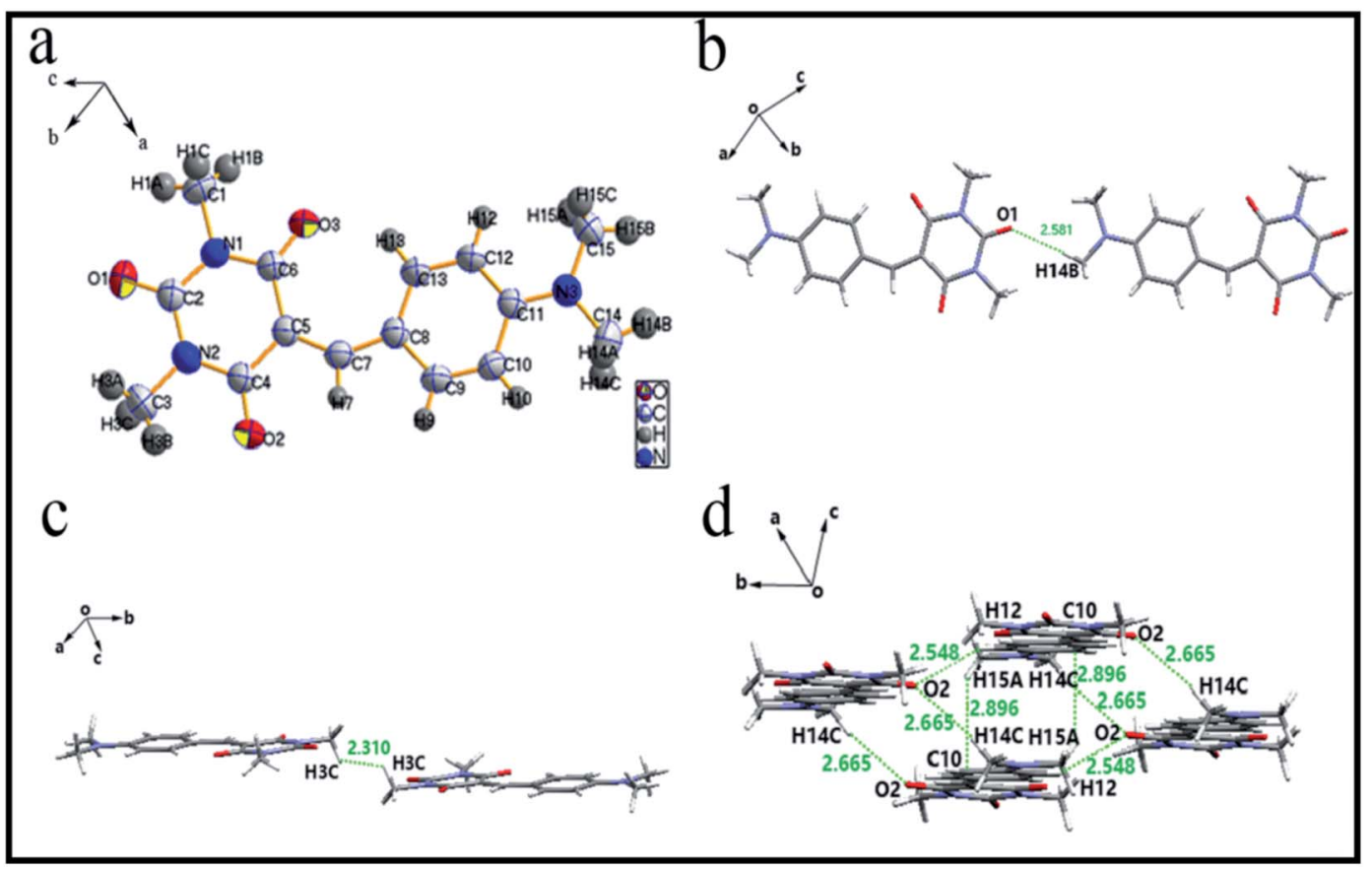

Fig. 6 ORTEP (thermal ellipsoids at the 50\% probability level) diagram (a), one-dimensional structure (b), two-dimensional network structure (c) and three-dimensional structure (d) of 2.

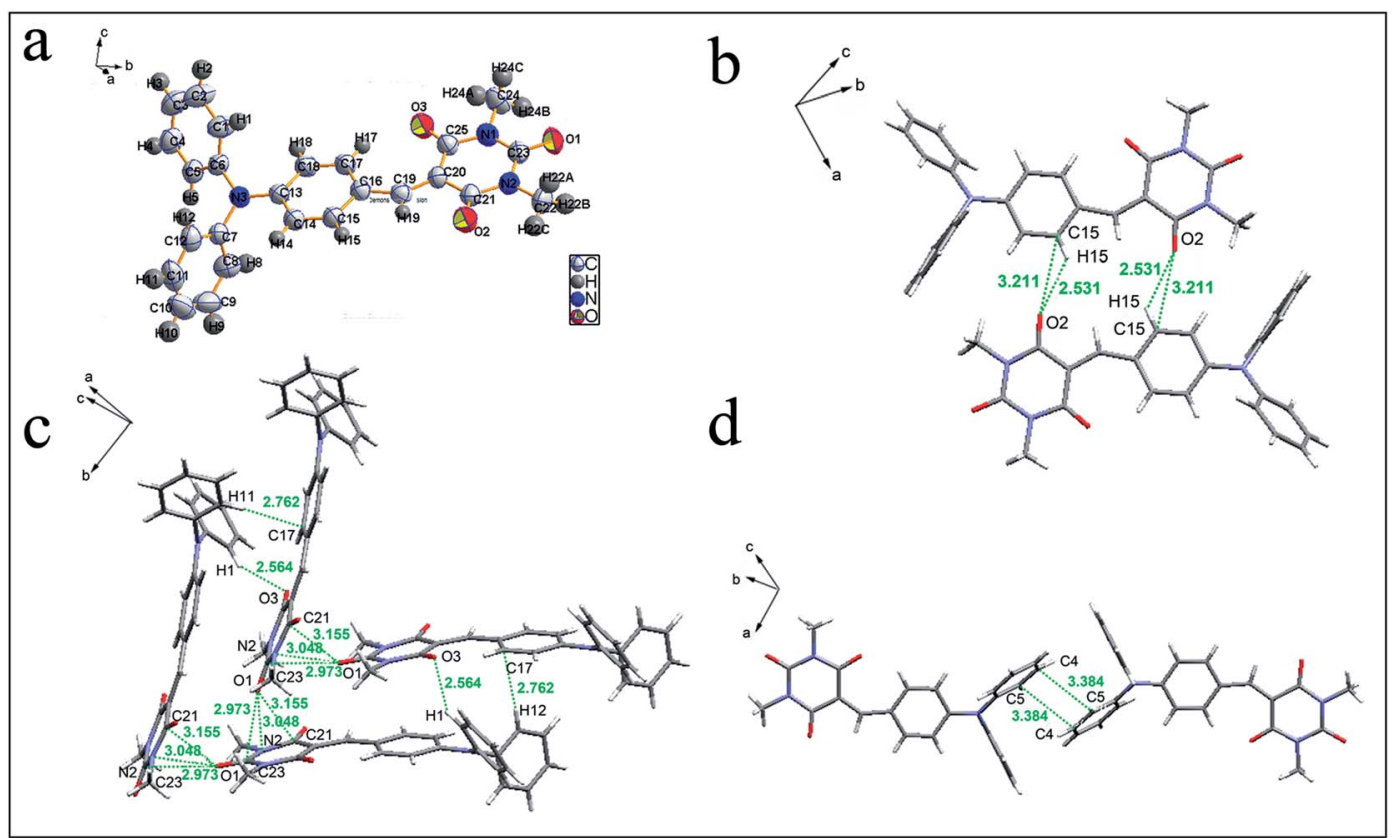

Fig. 7 ORTEP (thermal ellipsoids at the $50 \%$ probability level) diagram (a), one-dimensional structure (b), herringbone stacking structure (c) and $\pi-\pi$ interactions(d) of 4 .

intensity hardly changed in $1800 \mathrm{~s}$. These data showed that the nanoparticles exhibited excellent stability under light irradiation.

Compound $\mathbf{4}$ was then assessed for its capability to cell imaging by confocal laser scanning microscopy (CLSM). After incubation with Drosophila S2 cells with $\mathbf{4}$, compound $\mathbf{4}$ can be internalized into the cells, and red fluorescence can be detected intracellularly with minimal background autofluorescence signals. Presumably, compound $\mathbf{4}$ can be internalized into the endosome compartments and eventually move to the lysosome compartment of the cells within 2 hours. Indeed, the water insoluble character of compound $\mathbf{4}$ facilitates the passive cell 


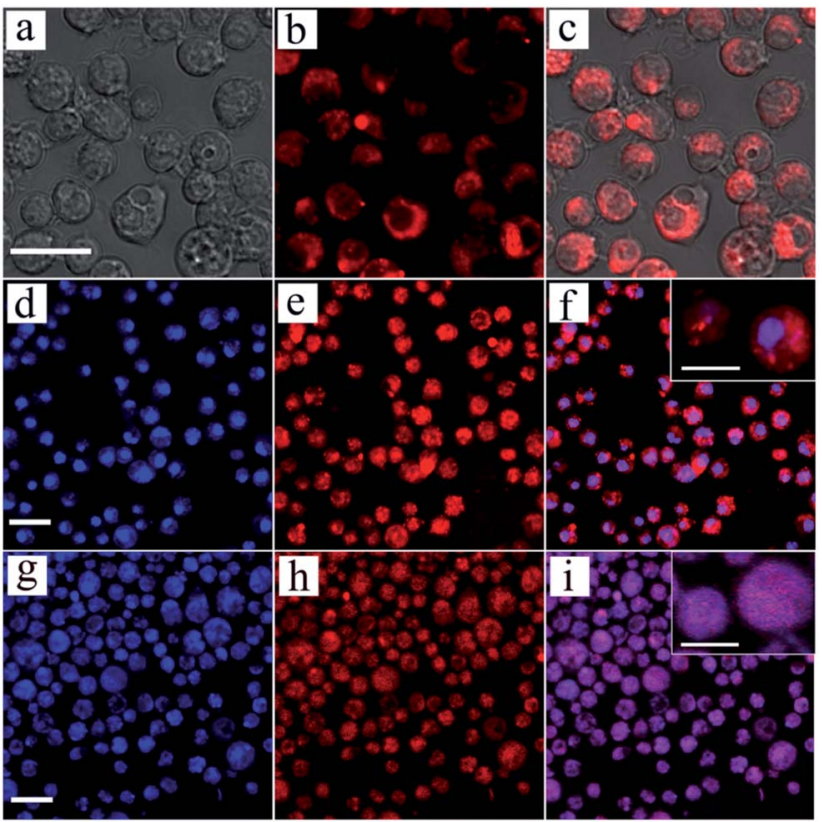

Fig. 8 (a-c) CLSM of Drosophila S2 cells incubated with compound 4 $(50 \mu \mathrm{M})$. (a)White-field channel, (b) fluorescence channel, (c) merged channel; $(d-f)$ co-localization experiment of Drosophila S2 cells incubated with compound 4 (red channel) and DAPI (blue channel) and the merged images (f) (inset is an enlarged view of (f)); $(\mathrm{g}-\mathrm{i}) \mathrm{co}-$ localization experiment of Drosophila S2 cells incubated with compound 4 (red channel) and Lysotracker Blue (blue channel) and the merged image (i). Scale bar $=20 \mu \mathrm{m}$; inset scale bar $=10 \mu \mathrm{m}$.

uptake and accumulation of the molecule into the lysosome. Indeed, co-localization experiments of compound $\mathbf{4}$ with Lysotracker Blue suggested they moved into the same intracellular space - lysosomes (Fig. 8g-i).
Intracellular co-localization experiment was performed with compound 4 and 4,6-diamino-2-phenylindole (DAPI). DAPI is a nucleus-targeting florescence probe, and accumulates selectively in the nucleus structure of cells. In the colocalization experiment, intense blue fluorescence can be detected in nucleus of the $\mathrm{S} 2$ cell, while no red fluorescence can be detected in the same region, suggesting that the compound $\mathbf{4}$ is unable to pass the nuclear membrane (Fig. 8f). The images show intense fluorescence was detected exclusively in the cytoplasm part of the Drosophila $\mathrm{S} 2$ cell, which might because of the molecule aggregation in the cells. The aggregated state tends to prevent fluorescence quenching resulted from non-radiative decay caused in aqueous environment, which is actual a common phenomenon in AIEbased bioimaging probes. ${ }^{48}$

\subsection{Theoretical calculation}

To have a better insight into their optical properties, we calculated frontier molecular orbitals by using the DFT at B3LYP/6-31G(d) basis set. The optimized geometries and HOMO/LUMO plots of 1-4 are illustrated in Fig. 9. The geometry optimized structures of 1-4 show highly twisted conformation, which are favorable for active intramolecular rotations of multiple phenyls and carbazole groups in solutions, thereby powerfully dissipating the excitons energy and making them nonemissive or weak emissive in solvents. The theoretical calculated HOMO levels of 1-4 are $-5.61,-5.53$, -5.47 , and $-5.44 \mathrm{eV}$, respectively. The energy gaps for 1-4 are $2.89,3.27,2.98$, and $3.01 \mathrm{eV}$, respectively. And the gaps estimated by absorption maxima of 1-4 are 3.81, 4.18, 4.12 and $4.10 \mathrm{eV}$, respectively. Therefore, the calculated values agree well with the test ones.

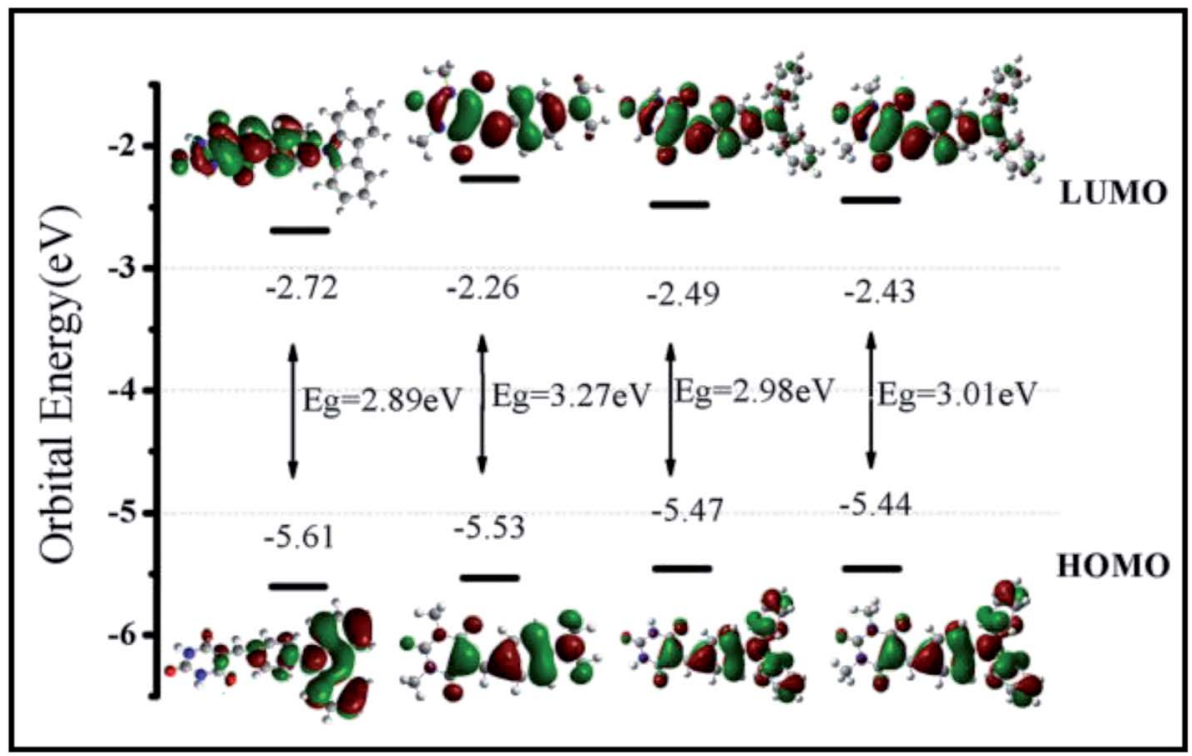

Fig. 9 Energy levels of HOMO and LUMO, energy gaps, and electron cloud distributions of molecules 1-4 calculated by the B3LYP/6-31G(d) program. ( $\mathrm{HOMO}=$ the highest occupied molecular orbital energy; $\mathrm{LUMO}=$ the lowest unoccupied molecular orbital energy; $E_{\mathrm{g}}=$ energy gap between HOMO and LUMO levels.) 


\section{Conclusions}

In summary, we report four luminogens 1-4 with typical AIE/ AIEE characteristics. Their emission wavelength changed with different $f_{\mathrm{w}}$, and their powders emit orange $(597 \mathrm{~nm}$ and 608 $\mathrm{nm}$ ) and red (620 $\mathrm{nm}$ and $637 \mathrm{~nm}$ ) light. UV-vis absorption spectra and theoretical calculation reveal the ICT possibilities of 1-4 from the donor units to the acceptor units. And we analyze the mechanisms of enhanced emission of these compounds are RIM. Furthermore, the theoretically calculated results agree with the measured optical properties. With the advantages of excellent biocompatibility and simplicity, compound 4 represents an excellent probe for Drosophila S2 cells imaging. Once entering lysosomes, the intramolecular motion of compound 4 will be restricted and the emission from compound $\mathbf{4}$ will be turned on.

\section{Acknowledgements}

This work was financially supported by the National Natural Science Foundation of China (No. 21276149, 21376125) and the Program for Scientific Research Innovation Team in Colleges and Universities of Shandong Province.

\section{Notes and references}

1 Z. F. Zhu, J. Qian, X. Y. Zhao, W. Qin, R. R. Hu and H. Q. Zhang, Stable and size-tunable aggregation-induced emission nanoparticles encapsulated with nano graphene oxide and applications in three-photon fluorescence bioimaging, ACS Nano, 2015, 10(1), 588-597.

2 D. D. Li, Y. P. Zhang, Z. Y. Fan, J. Chen and J. H. Yu, Coupling of chromophores with exactly opposite-luminescence behaviours in mesostructured organosilicas for highefficiency multicolour emission, Chem. Sci., 2015, 6, 60976101.

3 J. D. Luo, Z. L. Xie, J. W. Y. Lam, L. Cheng, H. Y. Chen and B. Z. Tang, Aggregation-induced emission of 1-methyl1,2,3,4,5-pentaphenylsilole, Chem. Commun., 2001, 18, 1740-1741.

4 Z. J. Zhao, B. R. He and B. Z. Tang, Aggregation-induced emission of siloles, Chem. Sci., 2015, 6, 5347-5365.

5 Y. P. Zhang, D. D. Li, Y. i. Li and J. H. Yu, Solvatochromic AIE luminogens as supersensitive water detectors in organic solvents and highly efficient cyanide chemosensors in water, Chem. Sci., 2014, 5, 2710-2716.

6 X. Y. Zhang, X. Q. Zhang, B. Yang, L. J. Liu, J. F. Hui, M. Y. Liu, et al., Aggregation-induced emission dye based luminescent silica nanoparticles: facile preparation, biocompatibility evaluation and cell imaging applications, RSC Adv. , 2014, 4, 10060-10066.

7 C. Wang, H. Y. Ji, M. S. Li, L. K. Cai, Z. P. Wang, Q. Q. Li, et al., A Highly Sensitive and Selective Fluorescent Probe for Hypochlorite in Pure Water with Aggregation Induced Emission Characteristics, Faraday Discuss., 2017, 196, 427-438.

8 Z. Y. Zhang, X. X. Song, S. P. Wang, F. Li, H. Y. Zhang, K. Q. Ye, et al., Two-dimensional organic single crystals with scale regulated, phase-switchable, polymorphismdependent, and amplified spontaneous emission properties, J. Phys. Chem. Lett., 2016, 7, 1697-1702.

9 X. Q. Zhang, X. Y. Zhang, B. Yang, J. F. Hui, M. Y. Liu, Z. G. Chi, et al., Novel biocompatible cross-linked fluorescent polymeric nanoparticles based on an AIE monomer, J. Mater. Chem. C, 2014, 2, 816-820.

10 P. J. Parrott, N. Y. Tan, R. R. Hu, J. Zeitler, B. Z. Tang and P. Emma, Direct evidence to support the restriction of intramolecular rotation hypothesis for the mechanism of aggregation-induced emission: temperature resolved terahertz spectra of tetraphenylethene, Mater. Horiz., 2014, 1, 251-258.

11 Y. R. Li, H. T. Zho, W. Chen, G. C. Sun, L. Sun and J. H. Su, A simple AIE-based chemosensor for highly sensitive and selective detection of $\mathrm{Hg}^{2+}$ and $\mathrm{CN}^{-}$, Tetrahedron, 2016, 72, 5620-5625.

12 H. T. Feng, J. H. Wan and Y. S. Zheng, $\mathrm{CH}_{3}-\pi$ Interaction of Explosives with Cavity of a TPE Macrocycle: The Key Cause for Highly Selective Detection of TNT, ACS Appl. Mater. Interfaces, 2014, 6(22), 20067-20074.

13 B. J. Xu, Z. G. Chi, X. Q. Zhang, H. Y. Li, C. J. Chen, S. W. Liu, et al., A new ligand and its complex with multi-stimuliresponsive and aggregation-induced emission effects, Chem. Commun., 2011, 47, 11080-11082.

14 J. Li, Y. Zhang, J. Mei, W. Y. Jacky, J. H. Hao and B. Z. Tang, Aggregation-induced emission rotors: rational design and tunable stimuli response, Chem.-Eur. J., 2014, 20, 1-9.

15 S. Lim, B. Z. Tang and Y. N. Hong, AIE Luminogens for Visualizing Cell Structures and Functions, ACS Symp. Ser., 2016, 1227, 199-216.

16 C. P. Ma, X. Q. Zhang, K. Wang, X. Y. Zhang, Y. H. Zhou, H. L. Liu and Y. Wei, A biocompatible cross-linked fluorescent polymer prepared via ring-opening PEGylation of 4-arm PEG-amine, itaconic anhydride, and an AIE monomer, Polym. Chem., 2015, 6, 3634-3640.

$17 \mathrm{~F}$. $\mathrm{Hu}$ and B. Liu, Organelle-specific bioprobes based on fluorogens with aggregation-induced emission (AIE) characteristics, Org. Biomol. Chem., 2016, 14, 9931-9944.

18 K. Wang, X. Y. Zhang, X. Q. Zhang, B. Yang, Z. Li, Q. S. Zhang, Z. F. Huang and Y. Wei, One-pot preparation of cross-linked amphiphilic fluorescent polymer based on aggregation induced emission dyes, Colloids Surf., B, 2015, 126, 273-279.

19 Y. J. Cho, S. Y. Kim, M. J. Cho, W. S. Han, D. W. Cho and S. O. Kang, Aggregation-induced emission of diarylamino$\pi$-carborane triads: Effects of Charge transfer and $\pi$ conjugation, Phys. Chem. Chem. Phys., 2016, 18, 9702-9708.

20 X. Q. Zhang, Z. Y. Ma, M. Y. Liu, X. Y. Zhang, X. R. Jia and Y. Wei, A new organic far-red mechanofluorochromic compound derived from cyano-substituted diarylethene, Tetrahedron, 2013, 69, 10552-10557.

21 X. Q. Zhang, X. Y. Zhang, B. Yang and Y. Wei, Facile Fabrication of Aggregation-induced Emission Based Red Fluorescent Organic Nanoparticles for Cell Imaging, Chin. J. Polym. Sci., 2014, 32, 871-879. 
22 W. L. Yang, J. H. S. K. Monteiro, A. de Bettencourt-Dias, V. J. Catalano and W. A. Chalifoux, Pyrenes, Peropyrenes, and Teropyrenes: Synthesis, Structures, and Photophysical Properties, Angew. Chem., 2016, 128, 10583-10586.

23 T. Weil, T. Vosch, J. Hofkens, K. Peneva and K. Müllen, The Rylene Colorant Family-Tailored Nanoemitters for Photonics Research and Applications, Angew. Chem., Int. Ed., 2010, 49, 9068-9093.

24 X. Y. Shen, Y. J. Wang, E. G. Zhao, W. Z. Yuan, Y. Liu and B. Z. Tang, Effects of Substitution with Donor-Acceptor Groups on the Properties of Tetraphenylethene Trimer: Aggregation-Induced Emission, Solvatochromism, and Mechanochromism, J. Phys. Chem. C, 2013, 117, 7334-7347.

25 K. T. Mahmudov, M. N. Kopylovich, A. M. Maharramov, M. M. Kurbanova, A. V. Gurbanov and A. J. L. Pombeiro, Barbituric acids as a useful tool for the construction of coordination and supramolecular compounds, Coord. Chem. Rev., 2014, 265, 1-37.

26 X. Zhang, E. S. Man Lai, R. Martin-Aranda and K. L. Yeung, An investigation of Knoevenagel condensation reaction in microreactors using a new zeolite catalyst, Appl. Catal., A, 2004, 261(1), 109-118.

27 S.-H. Kim, Y.-S. Kim, D.-H. Lee and Y.-A. Son, Synthesis and Optical Chromic Properties of New Barbituric Acid based Dye Molecules Having Push- $\pi$-Pull System, Mol. Cryst. Liq. Cryst., 2011, 550, 240-249.

28 W. Shi, S. Y. Zhao, Y. Su, Y. H. Hui and Z. F. Xie, Barbituric acid-triphenylamine adduct as an AIEE-type molecule and optical probe for mercury(II), New J. Chem., 2016, 40(9), 7814-7820.

29 K. X. Zhou, H. L. Fu, L. Feng, M. C. Cui, J. P. Dai and B. Liu, The synthesis and evaluation of near-infrared probes with barbituric acid acceptors for in vivo detection of amyloid plaques, Chem. Commun., 2015, 51, 11665-11668.

30 W. Z. Yuan, Y. Q. Tan, Y. Y. Gong, P. Lu, W. Y. Jacky, X. Y. Shen, et al., Synergy between twisted conformation and effective intermolecular interactions: strategy for efficient mechanochromic luminogens with high contrast, Adv. Mater., 2013, 25, 2837-2843.

31 S. K. Rajagopal, A. M. Philip, K. Nagarajan and M. Hariharan, Progressive acylation of pyrene engineers solid state packing and colour via $\mathrm{C}-\mathrm{H} \cdots \mathrm{H}-\mathrm{C}, \mathrm{C}-\mathrm{H} \cdots \mathrm{O}$ and $\pi-\pi$ interactions, Chem. Commun., 2014, 50, 8644-8647.

32 P. Alam, V. Kachwal and I. R. Laskar, A multi-stimuli responsive "AIE" active salicylaldehydebased schiff base for sensitive detection of fluoride, Sens. Actuators, B, 2016, 228, 539-550.

33 F. F. Han, R. Zhang, Z. M. Zhang, J. G. Su and Z. H. Ni, A new TICT and AIE-active tetraphenylethenebased Schiff base with reversible piezofluorochromism, RSC Adv., 2016, 6, 68178-68184.

34 Z. G. Song, R. T. Kwok, E. G. Zhao, Z. k. He, Y. N. Hong, W. Y. Lam, et al., A ratiometric fluorescent probe based on ESIPT and AIE processes for alkaline phosphatase activity assay and visualization in living Cells, ACS Appl. Mater. Interfaces, 2014, 6(19), 17245-17254.
35 J. Mei, Y. N. Hong, W. Y. Lam, A. J. Qin, Y. H. Tang and B. Z. Tang, Aggregation-induced emission: the whole is more brilliant than the parts, Adv Mater., 2014, 26(31), 5429-5479.

36 Y. J. Zhang, K. Wang, G. L. Zhuang, Z. Q. Xie, C. Zhang, F. Cao, et al., Multicolored-fluorescence switching of ICTtype organic solids with clear color difference: mechanically controlled excited state, Chem.-Eur. J., 2015, 21, 2474-2479.

37 S. S. Ragab, E. R. Thapaliya, Y. Zhang, S. C. Tang, J. B. McMahan, S. Syed, et al., Synthesis in living cells with the assistance of supramolecular nanocarriers, RSC Adv., 2016, 6, 32441-32445.

38 J. W. Hu, W. C. Lin, S. Y. Hsiao, Y. H. Wu, H. W. Chen and K. Y. Chen, An indanedione-based chemodosimeter for selective naked-eye and fluorogenic detection of cyanide, Sens. Actuators, B, 2016, 233, 510-519.

39 Y. X. Li, J. Jia and X. T. Tao, Intramolecular $\mathrm{H} \cdots \mathrm{H}$ steric hindrance modulated aggregate packing and optoelectronic properties in 1-naphthyl, 9-anthryl endcapped styrylarylene derivatives, CrystEngComm, 2012, 14, 2843-2848.

40 F. Qi, J. J. Lin, X. Q. Wang, P. Cui, H. Yan, S. W. Gong, et al., New AIE-active pyrimidine-based boronfluoride complexes with high solid-state emission and reversible mechanochromism luminescence behavior, Dalton Trans., 2016, 45(17), 7278-7284.

41 Y. Z. Xie, G. G. Shan, P. Li, Z. Y. Zhou and Z. M. Su, A novel class of $\mathrm{Zn}(\mathrm{II})$ Schiff base complexes with aggregationinduced emission enhancement (AIEE) properties: Synthesis, characterization and photophysical/ electrochemical properties, Dyes Pigm., 2013, 96, 467-474.

42 P. Y. Gu, C. J. Lu, Z. J. Hu, N. J. Li, T. T. Zhao, Q. F. Xu, et al., The AIEE effect and two-photon absorption (TPA) enhancement induced by polymerization: synthesis of a monomer with ICT and AIE effects and its homopolymer by ATRP and a study of their photophysical properties, $J$. Mater. Chem. C, 2013, 1(14), 2599-2606.

43 K. Fujii, N. Iyi, R. Sasai and S. Hayashi, Preparation of a novel luminous heterogeneous system: rhodamine/coumarin/ phyllosilicate hybrid and blue shift in fluorescence emission, Chem. Mater., 2008, 20, 2994-3002.

44 W. Z. Yuan, Y. Y. Gong, S. M. Chen, X. Y. Shen, W. Y. Lam, P. Lu, et al., Efficient Solid Emitters with AggregationInduced Emission and Intramolecular Charge Transfer Characteristics: Molecular Design, Synthesis, Photophysical Behaviors, and OLED Application, Chem. Mater., 2012, 24, 1518-1528.

45 S. Vyas, R. Gutzler, J. Nuss, K. Kernab and V. Bettina, Optical gap in herringbone and $\pi$-stacked crystals of [1]benzothieno $[3,2-b]$ benzothiophene and its brominated derivative, CrystEngComm, 2014, 16, 7389-7392.

46 C. W. Chang, C. J. Bhongale, C. S. Lee, W. K. Huang, C. S. Hsu, W. G. Diau, et al., Relaxation Dynamics and Structural Characterization of Organic Nanobelts with Aggregation-Induced Emission, J. Phys. Chem. C, 2012, 116, 15146-15154. 
47 K. S. Patil, P. G. Mahajan and S. R. Patil, Fluorimetric detection of $\mathrm{Sn}^{2+}$ ion in aqueous medium using Salicylaldehyde based nanoparticles and application to natural samples analysis, Spectrochim. Acta, Part A, 2017, 170, 131-137.
48 D. B. Chao and Y. X. Zhang, Anion-induced emissive nanoparticles for tunable fluorescence detection of pyrophosphate and bioimaging application, Sens. Actuators, B, 2017, 242, 253-259. 